
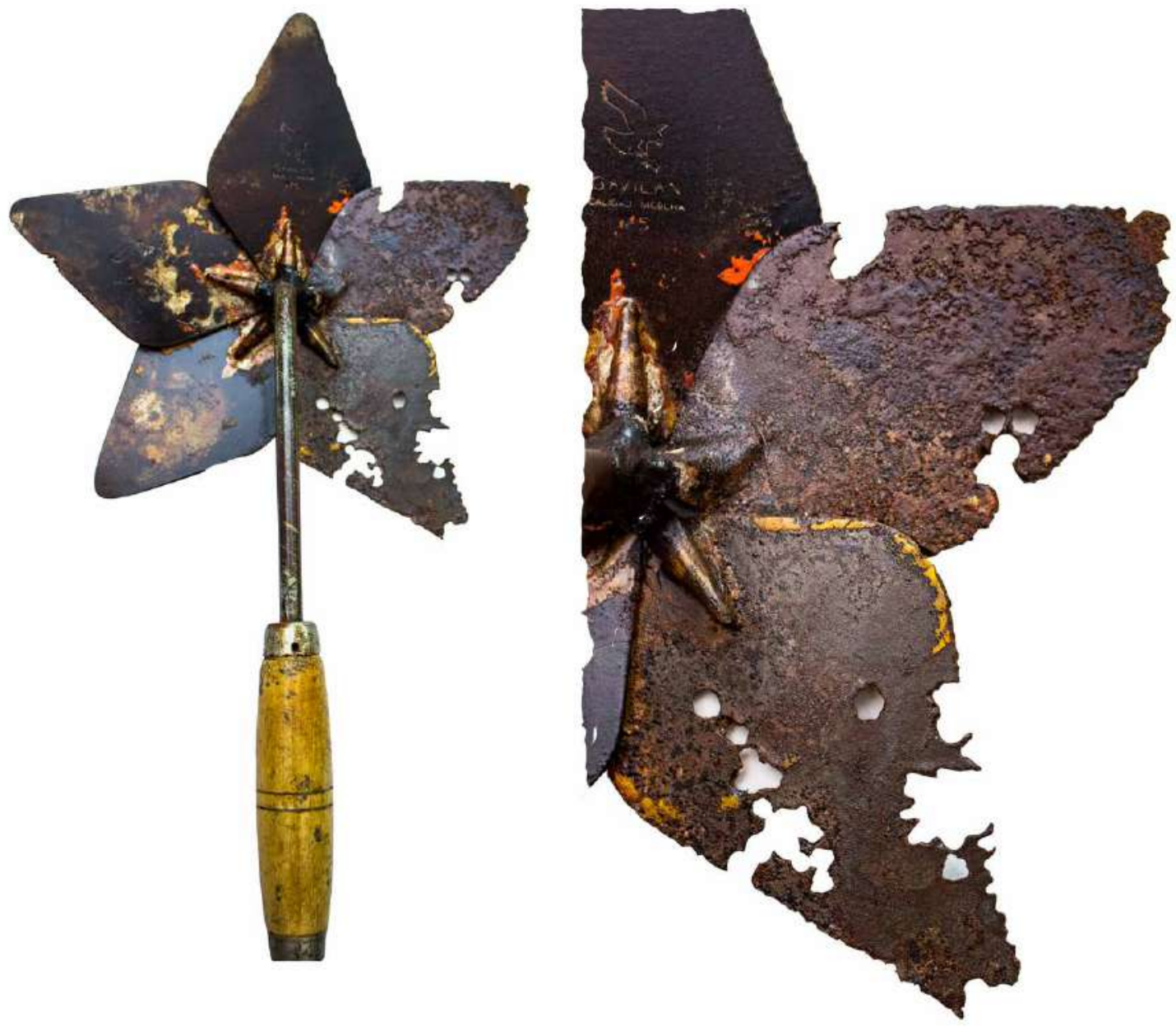

Yamith Quiroz David

Nuevas vegetaciones I

De la serie El mito de flora

Escultura, palustres, cabo de madera

$40,5 \times 24 \times 10 \mathrm{~cm}$

2020

Medellín 


\title{
Pueblos indígenas. Reconocimiento y tensiones político-normativas al interior del espacio público en Chile, 1990-2010*
}

\author{
Catalina Daniela Riquelme Tapia (Chile)** \\ Mario Samaniego Sastre (Chile) ${ }^{* * *}$
}

\section{Resumen}

A partir de la teoría fundamentada, se presenta una reflexión sobre las relaciones políticas entre el Estado chileno y el pueblo mapuche en el periodo 1990-2010, específicamente, se abordan estas relaciones según las tensiones generadas entre estos actores en el espacio público-político. Para ello se ha requerido, por un lado, observar los fenómenos emergentes de carácter étnico —distintos movimientos y sus respectivas demandas de reconocimiento-y, por el otro, analizar el rol de un Estado con características liberales como el chileno. Ante la negación política del reconocimiento multicultural en Chile, las tensiones que lo han impedido pueden ser enfrentadas si, en efecto, el vigente liberalismo, marcadamente monocultural, se apropiara de ciertos desarrollos del multiculturalismo, esto es, las tensiones encontrarían vías de escape para ser abordadas y el liberalismo no tendría

[ 46 ] por qué traicionarse a sí mismo.

\section{Palabras clave}

Políticas Públicas; Multiculturalismo; Espacio Público-Político; Políticas de Reconocimiento; Política Étnica; Chile.

Fecha de recepción: octubre de 2019 - Fecha de aprobación: mayo de 2020

\footnotetext{
* Este artículo se deriva del proyecto de investigación La comunidad a debate: entre el pensamiento post-fundacionalista y la filosofía intercultural, Código 412-3850, 2018, Vicerrectoría de Investigación y Posgrado, Universidad Católica de Temuco, Chile.

** Licenciada en Ciencia Política. Magíster en Trabajo Social: Políticas Públicas, Familia e Interculturalidad. Docente asociada investigadora del Departamento de Sociología y Ciencia Política, Universidad Católica de Temuco, Chile. Correo electrónico: criquelmetapia2013@gmail.com - Orcid: 0000-0002-7058-4924

${ }^{* * *}$ Licenciado en Filosofía. Magíster en Ciencias Sociales Aplicadas. Estudios de Doctorado en Ética y Filosofía Política. Docente investigador del Departamento de Antropología, Universidad Católica de Temuco, Chile. Correo electrónico: msamanie@uct.cl - Orcid: 0000-0002-4695-1157
} 


\title{
Cómo citar este artículo
}

Riquelme Tapia, Catalina Daniela y Samaniego Sastre, Mario. (2020). Pueblos indígenas. Reconocimiento y tensiones político-normativas al interior del espacio público en Chile, 1990-2010. Estudios Políticos (Universidad de Antioquia), 59, pp. 46-73. DOI: 10.17533/udea.espo.n59a03

\section{Indigenous Peoples. Recognition and Normative-Political Tensions within Public Space in Chile, 1990-2010}

\begin{abstract}
Based on the grounded theory, this study introduces a reflection on the political relations between the Chilean State and the Mapuche people in the period 1990-2010. These relations are addressed in analyzing the tensions between these actors in the public-political space. To this aim, on the one hand, the ethnic nature of emerging phenomena - different movements and their respective demands for recognition- are observed and, on the other hand, the role of a State with liberal characteristics such as the Chilean one is analyzed. In the face of the political denial of the multicultural recognition in Chile, the study proposes that the tensions that have prevented this recognition can be faced if the current liberalism, which is markedly monocultural, appropriates certain developments of multiculturalism. Accordingly, the tensions would find ways to be addressed without rejecting liberalism.
\end{abstract}

\section{Keywords}

Public Politics; Multiculturalism; Public-Political Space; Recognition Policies; Ethnic Policy; Chile. 


\section{Introducción}

El estudio de la relación entre los pueblos indígenas, especialmente el pueblo mapuche, y el Estado chileno ha sido trabajado a partir de muchas de las aristas que conforman esta compleja relación (Bengoa, 2008; Pinto, 2000; Pavez, 2008; Boccara y Seguel-Boccara, 1999; Zavala, 2015). Este artículo analiza las relaciones políticas que se dieron entre estos actores, particularmente, la dinámica política del Estado chileno con el pueblo mapuche a partir del retorno a la democracia hasta 2010. El periodo es relevante ya que, como se verá más adelante, se perdió la oportunidad de encauzar, deliberativa y participativamente, los conflictos que han jalonado históricamente esta relación.

Desde el punto de vista teórico-político, esta indagatoria cobra especial relevancia debido a las distintas ideas políticas vinculadas generalmente a movimientos sociales que han surgido a partir de la década de 1980, tales como políticas de la diferencia, demandas de reconocimiento, revisiones multiculturalistas del liberalismo (Taylor, 2009; Cohen, 2009), entre otras que han tensionado la forma de concebir la política y el papel de los distintos actores en el marco de los espacios público-políticos, ${ }^{1}$ además de haber

[ 48 ] puesto en jaque a los modelos políticos que han ordenado la convivencia desde el liberalismo clásico (Rawls, 1995), que en Chile y en gran parte de América Latina ha operado. Así, toda política se ha visto permeada por un liberalismo que ha actuado y actúa como frontera intransgredible para entender el desarrollo y avance de los fundamentos y propuestas políticas.

Específicamente, lo que se intentará mostrar en este artículo son las tensiones evidenciadas en el espacio público-político en el marco de las relaciones entre el pueblo mapuche y el Estado chileno. Estas tensiones hacen referencia a aquella situación de oposición u hostilidad entre el Estado, a través de su institucionalidad política y normativa, y el pueblo mapuche. Estas tensiones serán estudiadas de manera analítica y social: por una parte, el análisis político permite evidenciar tensiones históricas en las relaciones de poder entre ambos actores $y$, por la otra, un análisis de racionalidad normativa que permite entender las respuestas que la institucionalidad ha resuelto a través de políticas públicas a las demandas históricas de reconocimiento. Así,

1 Los asuntos comunes, la deliberación, la agencia y el desarrollo de aprendizajes son elementos constitutivos de lo público-político (Rincón, 2008). 
se requiere observar los fenómenos emergentes de carácter étnico y analizar el rol de un Estado con características democráticas liberales.

Si bien este estudio se circunscribe a la realidad chilena, puede ser de interés para otras realidades latinoamericanas e, incluso, paradigmático, ya que con independencia de las diferentes realidades jurídicas que viven las diversas sociedades indígenas de América Latina, en la actualidad, de manera casi transversal, deben enfrentar problemáticas comunes - extractivismo, conflictos socioambientales, entre otros - producto de las políticas económicas facilitadas y promovidas por modelos liberales. Chile puede ser un buen espejo donde observar las consecuencias de la aplicación de este tipo de políticas, las que, transgrediendo el liberalismo político clásico, han tensionado el espacio público-político chileno.

La hipótesis aquí planteada es que las tensiones originadas al interior del espacio público, en un contexto de democracia liberal fuertemente influenciada por la transición democrática, la configuración de las alianzas partidarias, las políticas públicas originadas y su relación con el pueblo mapuche han impedido un reconocimiento multicultural en Chile. Asimismo, estas tensiones pueden ser intervenidas si, en efecto, el liberalismo, marcadamente monocultural, se apropiara de ciertos desarrollos del multiculturalismo, esto es, las tensiones encontrarían vías para ser abordadas y el liberalismo no tendría por qué traicionarse a sí mismo, sino que, por el contrario, desarrollaría todo su potencial. Este análisis y reflexión se enmarca en un realismo político, advirtiendo las limitaciones que el multiculturalismo liberal tiene en relación con las demandas de los pueblos indígenas. Este es un camino que, por el momento, puede oxigenar un conflictivo panorama político y social donde no se atisban vías de escape.

Según estas coordenadas, el planteamiento de este artículo pone énfasis en la dimensión institucional de la problemática, esto es, prioriza como fuentes de información y análisis las acciones políticas de distinta naturaleza emanadas de los distintos gobiernos en el periodo señalado. Es claro que esta decisión no revela suficientemente todo un conjunto de voces, movimientos sociales y organizaciones políticas mapuches y no mapuches, que a modo de constelación polifónica denuncian, proponen y resisten frente a la renovada persistencia de la colonialidad del poder, el impacto económico en territorios y subjetividades y las prácticas extractivistas (Pairicán, 2014). El enfoque institucional para abordar la problemática en juego, propio de una de las 
tradiciones disciplinarias de la ciencia política, se ha desarrollado menos que aquellos ligados a la historia social y a la antropología sociocultural; poner en comunicación la pluralidad de ambas perspectivas encaminará a una comprensión más cabal de esta problemática.

En términos metodológicos, es necesario dar cuenta de una serie de acontecimientos que el contexto nacional específico facilita a través de la literatura y de sus fuentes de carácter cualitativo mediante el análisis de los contenidos de fuentes secundarias, tales como entrevistas, análisis de bibliografía, papers, libros sobre la materia y medios de prensa. Lo anterior se enmarca en la teoría fundamentada, mediante un análisis individual y transversal de las categorías surgidas desde los polos temáticos que permiten establecer explicaciones e interrelaciones de los diferentes aspectos del fenómeno estudiado (Strauss y Corbin, 2002). Por último, es importante señalar que el uso de fuentes secundarias responde, en su mayoría, a literatura y enfoques utilizados desde la ciencia política.

\section{Tensiones en las dinámicas histórico-políticas}

En lo que sigue, y siendo fieles al planteamiento institucionalista, se [ 50 ] exponen algunas tensiones teóricas clásicas que enfrentan a Rawls (1995) con Taylor (1997) y que permiten entender con claridad las disputas sociales y políticas que conflictúan al Estado y al pueblo mapuche.

En primer lugar, la modernidad se refiere a la instalación de un modelo político que encuentra en la razón pública ${ }^{2}$ su principio fundamental y con la cual se asocia de manera natural lo que se ha denominado autonomía del individuo. De esta manera, es el Estado, a través de sus leyes, el que debe garantizar un amplio ámbito de acción para el individuo y su plena libertad de acción. Si bien el liberalismo reconoce que la cultura política de una sociedad democrática, siempre está marcada por una diversidad de doctrinas religiosas, filosóficas y morales opuestas entre sí, igualmente reconoce que en muchas oportunidades estas son antagónicas. Al decir de los liberales, estas diversas doctrinas que son perfectamente razonables son el inevitable resultado, a largo plazo, de las capacidades de la razón humana y su actividad dentro del trasfondo de instituciones libres y duraderas. La misma doctrina postula que

\footnotetext{
${ }^{2}$ La razón pública es entendida como la que guía la toma de decisiones políticas en una sociedad democrática (Arregui, 1997, junio 29).
} 
primará siempre el apego a la Constitución y a las leyes que determinarán la justicia, lo que generaría tensiones al enfrentarse distintas maneras de ver el mundo (Rawls, 1995). Rawls las ha definido y categorizado como tensiones de compromiso, es decir, como aquellas que surgen en la sociedad entre sus exigencias de justicia y los legítimos intereses de los ciudadanos.

Ante esta situación, y como señala Bauman (2000), en la era de la globalización se han producido una serie de cambios inevitables que han interpelado los supuestos de la política, señalando incluso la disolución de lo que se ha conocido hasta ahora como Estado-nación. La reivindicación de lo cultural ha suscitado y puesto en marcha movimientos de carácter étnico en todo el mundo, que han venido a cuestionar los principios universalistas que han regido las democracias liberales.

Samuel Huntington (1996) sostiene que la dimensión fundamental y más peligrosa de la política global que está surgiendo es el conflicto entre grupos de civilizaciones diferentes. Por su parte, Díaz-Polanco (2006) señala que el renacimiento de las identidades, los movimientos multiculturalitas y la generación de políticas de reconocimiento tensionan actualmente el espacio público-político en el escenario mundial y local, tensiones que adquieren una diversidad de morfologías en virtud de la contextualidad de las tensiones y lo polisémico del concepto multiculturalismo, tanto en el ámbito teórico como normativo. Esto abre un amplio abanico de posibilidades para abordar la situación. Así, en América Latina todo el interculturalismo crítico (Walsh, 2009) denuncia al multiculturalismo como una elaboración funcional al liberalismo de facto. Por el contrario, en el ámbito anglosajón, Meer y Monood (2012) rechazan las críticas del interculturalismo al multiculturalismo, al señalar que las diferencias entre ambas propuestas no se sostienen. Como ya se ha indicado, entre las múltiples posibilidades de análisis, se ha optado por vislumbrar el rendimiento ético-político del liberalismo político.

La racionalidad dominante en el liberalismo y presente en las instituciones del Estado ha carecido históricamente de toda sensibilidad moral, adoptando una forma de liberalismo político que impide visualizar en el espacio público formas distintas de comprender el mundo y, por tanto, la resistencia a las demandas culturales por el reconocimiento. El velo de ignorancia sería expresión de esto (Rawls, 1995). Estas tensiones parecen ser cada vez más profundas y críticas, y serían expresión de la crisis que vive el espacio públicopolítico. Las demandas de reconocimiento serían manifestación de las tensiones 
que este escenario genera. No obstante, en efecto, habla de reconocimiento, de un reconocimiento público en tres aspectos: i) cuando la sociedad está regulada por principios públicos de justicia y sus ciudadanos aceptan estos principios y saben que los demás también; ii) cuando las creencias generales son compartidas por todos respecto de la justicia y las instituciones; y iii) cuando se reconoce una concepción política de justicia al reflexionar por qué actuamos de una manera y no de otra. Para el multiculturalismo, en cambio, el reconocimiento se fundamenta en la tesis ontológica de que la identidad es previa a la razón, con lo que el reconocimiento pasa a ser una demanda ante la que el Estado debe definirse en favor de la diversidad, esto es, garantizar igual respeto por todas las diferencias culturales (Taylor, 1997).

Pareciera ser entonces que una de las tensiones ${ }^{3}$ más significativas que impiden el reconocimiento se articula en la siguiente pregunta: ¿dónde nos situamos para entender y justificar la construcción de la identidad? Desde una perspectiva liberal, el Estado, más que vincular — posibilidad de deliberación en condiciones de igualdad- las diversas pluralidades comprensivas (Rawls, 1995), ha tenido como efecto el distanciamiento entre un «nosotros» creado y basado en principios políticos, y un «ellos» plural y comprensivo. Así, el «entre nos» del que habla Hannah Arendt (1997), en tanto acción concertada desde el pluralismo, desaparece inevitablemente en esta ecuación llamada modernidad, donde emergen nuevas demandas sociales de carácter étnico, pero donde el Estado ha sido incapaz de comprender que se debe transitar, en materia política y normativa, hacia la creación de espacios de deliberación que consideren realmente a todos los actores y que privilegie el sentido moral en la construcción de identidad como forma de respeto hacia el otro, es decir, que si bien en un Estado con características democráticas liberales prima la racionalidad, es necesario transitar hacia una política del reconocimiento (Taylor, 2009). La política así entendida produciría una disolución o subversión de la totalización social: el conflicto político es la tensión entre un cuerpo social estructurado en el cual cada parte tiene un lugar y «la parte de ninguna parte» que perturba ese orden en nombre del principio vacío de la universalidad, la igualdad de principio de todos los hombres en tanto seres que se valen de la palabra (Etchegaray, 2014).

\footnotetext{
${ }^{3}$ Comprender las tensiones al interior del espacio público implica la oposición u hostilidad entre el Estado, a través de su institucionalidad política y normativa, y los pueblos indígenas —en especial, el pueblo mapuche-, lo cual tensiona toda búsqueda de encuentro y reconocimiento entre dos actores diversos.
} 
Lo anterior requiere categorizar la cultura y sus prácticas. Para los liberales la cultura en el ámbito de la política tiene que ver con la cultura pública, esto es, el fondo compartido de ideas básicas y principios implícitamente reconocidos (Rawls, 1995). Cualquier consideración respecto de las particularidades socioculturales es omitida, quedando relegadas a un asunto privado de cada persona y grupo. Es en el espacio público donde se arriesgan las decisiones políticas, por tanto, estaríamos limitados por las posibilidades de la cultura liberal. Situar en el trasfondo las diferencias culturales ha sido tradicionalmente argumento para justificar la necesaria neutralidad del espacio público-político, neutralidad que no es tal, ya que constituye un determinado punto de vista que, además, hunde sus raíces en un determinado contexto cultural e histórico.

Las consecuencias de estas diferencias sobre el lugar de la cultura abren la vía para vislumbrar otras tensiones: los liberales definen al individuo como anterior a toda comunidad; es el individuo en la posición original. Las concepciones multiculturales y, sobre todo, comunitaristas inscriben al «yo» como parte de una colectividad abarcando «más de un ser humano individual afirmando la existencia de responsabilidades y obligaciones con la comunidad» (Sandel, 2000); dicho de otro modo, para los comunitaristas, llegar a ser una individualidad en el marco de un contexto cultural. En cambio, para los liberarles el individuo se sostiene en su propia individualidad. Necesariamente, y de la mano de esto, el concepto y la práctica de libertad entran en tensión. Para el liberalismo, la libertad tiene que ver con la concepción política de la persona, es decir, los ciudadanos son libres en la medida en que se conciben a sí mismos como poseedores de la capacidad moral para tener una concepción del bien, son libres si pueden asumir la responsabilidad de sus fines, son libres en la medida en que se consideran a sí mismos fuentes de reclamaciones válidas, siempre y cuando estas concepciones no salgan de los márgenes permitidos por la concepción política de la justicia. Se es libre en la medida en que se garantizan libertades básicas e igualitarias para todos (Rawls, 1995). Frente a esto, Taylor (2009) considera que ser libre es permitir que los individuos o los colectivos desarrollen la capacidad de rechazar o modificar la identidad cultural que se ha heredado o impuesto y, por ello, la dignidad humana exige que las instituciones democráticas liberales no sean represivas ni discriminatorias y sí, en cambio, deliberativas. Libertad supone capacidad para definirme como diferente. 
En síntesis, cuatro son las tensiones señaladas, las que limitan severamente la oportunidad de gestionar relaciones políticas sobre la base de alguna expectativa común: la identidad en el espacio público, el lugar de la cultura, la relación individuo-comunidad y la concepción y práctica de la libertad. Si bien todas ellas forman parte de una misma dinámica, para efectos del análisis, se referirá particularmente a cada una de ellas como medios para destacar las tensiones enunciadas.

\section{Configuración de tensiones: hechos políticos}

A continuación, se señala un conjunto de hitos políticos que representa la historia de esta relación en el tiempo referido que da cuenta con nitidez de las tensiones esbozadas, debido a que actúan como trasfondo para comprender y validar la hipótesis planteada.

\subsection{Acuerdo de Nueva Imperial, 1989}

Suscrito por el entonces candidato a la presidencia Patricio Aylwin, representante del Partido Demócrata Cristiano, y por los representantes de organizaciones indígenas del país — mapuches, huilliches, aymaras y rapanuis-

[ 54 ] (Aylwin, 1989). Este acuerdo comprometió a «hacer suya la demanda de los Pueblos Indígenas de Chile [...]» (p. 1). ${ }^{4}$ El mayor hito se comienza a configurar con la elección de Patricio Aylwin (1990-1994) —Concertación de Partidos por la Democracia - en 1989 como el primer presidente elegido desde el retorno a la democracia, lo cual tuvo vital relevancia desde el punto de vista de la agenda política (Figueroa, s. f.). Los compromisos asumidos en campaña desde el punto de vista de la política indígena se convirtieron en un importante compromiso de gobierno, razón por la cual el 27 de mayo de 1990 se creó la Comisión Especial de Pueblos Indígenas (CEPI), cuya función fue asesorar la determinación de las políticas de gobierno respecto de los grupos étnicos indígenas que integran la sociedad chilena (Decreto Supremo 30 del 17 de mayo de 1990). De esa forma, haciendo uso de su recurso de autoridad legal-formal, el Ejecutivo definió la forma y los mecanismos que se utilizarían para llegar a acuerdos en torno a la política indígena (Figueroa,

${ }^{4}$ Especialmente en lo referido al reconocimiento constitucional de los pueblos indígenas y de sus derechos económicos, sociales y culturales fundamentales, la creación de una Corporación Nacional de Desarrollo Indígena (Conadi) y la Creación de una Comisión Especial para los Pueblos Indígenas (CEPI). 
2016). Fue el surgimiento de una tensión que impidió que los pueblos indígenas se presentaran en condiciones para instalar su voz, lo que hubiera supuesto la presencia en lo público de una práctica deliberativa. Su identidad quedó desplazada.

\subsection{Congreso de Pueblos Indígenas}

Celebrado en Temuco el 18 de enero de 1991 y convocado para discutir y sancionar las propuestas de las organizaciones allí representadas sobre los contenidos de la nueva Ley Indígena, ${ }^{5}$ su naturaleza y las funciones de la Corporación de Desarrollo Indígena (Correa 2017, marzo 12). En sus resoluciones, el Congreso de los Pueblos Indígenas sancionó un documento que establecía los principales contenidos que debería incluir la nueva Ley Indígena. Los partidos políticos presentes en el Congreso, en especial aquellos opositores al gobierno — representantes de los intereses empresariales-, mostraron su resistencia a este proceso, tal como lo señaló el entonces ministro secretario general Enrique Correa: «la Ley Indígena nace en el contexto de la transición política a la democracia» (Correa, 2017, marzo 12). Por tanto, aun cuando existía voluntad del Gobierno por avanzar en las demandas de los pueblos indígenas, la estabilidad política de la transición dependía en buena medida de que las reformas que se iniciaban deberían ser consensuadas por los actores políticos representados en el Parlamento, es decir, la generación de acuerdos tácitos, que impidieron que la diferencia indígena tuviera una presencia en lo público-político.

\subsection{El Gobierno ingresa proyecto de ley con modificaciones}

La tramitación iniciada en la Cámara de Diputados, aprobada en general, fue objeto de múltiples reparos, lo que obligó a negociar un «acuerdo marco» entre los representantes de todos los partidos (Correa, 2017, marzo 12). En noviembre de 1992 el Gobierno ingresó un nuevo texto que incluía los acuerdos alcanzados. La ley siguió su trámite en ambas cámaras, introduciéndose diversas modificaciones. En este clima de constante tensión, el cinco de octubre de 1993 se publicó la Ley Indígena (Ley 19.253), la cual nació cercenada para poder otorgar un verdadero reconocimiento a los pueblos indígenas, dado que sus propuestas no fueron visibilizadas.

\footnotetext{
${ }^{5}$ Alrededor de la CEPI, y de acuerdo con los antecedentes proporcionados por un dirigente indígena, se trabajaron catorce iniciativas de proyectos de ley.
} 


\subsection{Corporación Nacional de Desarrollo Indígena (Conadi) como coordinador de la política indígena y no como interlocutor válido}

La Ley Indígena señala a los indígenas como descendientes de las agrupaciones humanas que existen y habitan el territorio nacional. Dentro de su articulado se establece el reconocimiento a las principales etnias indígenas de Chile. ${ }^{6}$ Para dar cumplimiento a lo anterior, se estableció, como deber de la sociedad en general y del Estado en particular, respetar, proteger y promover el desarrollo de los indígenas, sus culturas, familias y comunidades, adoptando las medidas adecuadas para tales fines (Ministerio de Planificación y Cooperación Social, 5 de octubre de 1993). Aun cuando la Ley Indígena fue promulgada, generó insatisfacción en un amplio sector de los pueblos indígenas por no considerar aspectos estratégicos que debían ser incluidos en la agenda del Cobierno y ser plasmados en la Ley. Esta situación engloba todas las tensiones referidas. Conadi pasó a ser un coordinador de las políticas indígenas y no un interlocutor válido respecto de las demandas que los pueblos tenían, ${ }^{7}$ debido a las escasas facultades que le fueron otorgadas en materia de reconocimiento político. Desde el mundo indígena se criticó esta carencia, [ 56 ] (Figueroa, s. f.). ya que la Ley solo habla de etnias diferenciadas cultural y lingüísticamente

Otro aspecto no menor se refería a la participación de los pueblos indígenas y su carácter vinculante en la toma de decisiones respecto de su rol como actores políticos, ya que esta participación se redujo al Consejo Nacional de la Conadi. ${ }^{8}$ Solo ocho de los diecisiete representantes eran miembros de pueblos indígenas, los nueve restantes, incluido el director

\footnotetext{
${ }^{6}$ Aimara, Rapa Nui o pascuenses, comunidades atacameñas, Quechuas y Collas del norte del país, las comunidades Kawashkar o Alacalufe y Yámana o Yagán de los canales australes.

${ }^{7}$ Las demandas de los pueblos indígenas, en especial del pueblo mapuche, están vinculadas al reconocimiento constitucional como pueblo, la autonomía y la autodeterminación en cuanto al territorio que habitan. José Bengoa (2008) plantea que la búsqueda de la autonomía política y territorial del pueblo mapuche desemboca necesariamente en el reconocimiento de este pueblo como un «otro», distinto del resto de la sociedad chilena.

${ }^{8}$ La Dirección Superior de la Conadi se encuentra a cargo del Consejo Nacional integrado por el director nacional de la Corporación — nombrado por el presidente de la República—, los subsecretarios o su representante - especialmente nombrados-, tres consejeros designados por el presidente de la República y ocho representantes indígenas - cuatro mapuches, un aimara, un atacameño, un rapanui y uno con domicilio en un área urbana del territorio nacional-
} 
nacional, representaban al Ejecutivo, inclinando la balanza al Gobierno de turno, lo que en materia de decisiones influiría a la hora de definir las políticas y aprobar los diversos programas, así como la propuesta de reformas legales en materia indígena. Como consecuencia de lo anterior, las reivindicaciones no asumidas en la Ley de 1993 se convirtieron en el corazón de las demandas y conflictos que hoy están planteados por las distintas expresiones del movimiento mapuche: su diferencia no era asumida como tal.

\subsection{Primeras tomas de terreno por parte de indígenas mapuches}

Con la llegada de Eduardo Frei Ruiz-Tagle a la Presidencia (1994-2000) se evidenciaron contradicciones entre su agenda económica y las demandas de los pueblos indígenas, sumada a la tensión entre las aspiraciones de la política indígena y la deficiente institucionalidad pública definida para ella (Figueroa, 2016).

El periodo de Frei se vio marcado por una serie de hechos vinculados a su programa de gobierno, en particular, el crecimiento económico, la innovación y la inversión privada, con especial énfasis en la construcción de grandes obras de infraestructura —en su mayoría, para la utilización de recursos naturales como el agua (hidroeléctricas) y la producción maderera a gran escala (emplazamiento de forestales) — situadas mayormente en los territorios de mayor población indígena mapuche. Proceso que, tal como lo señaló un dirigente indígena, mientras que para el Estado la tierra se convierte en un recurso que potencia el crecimiento económico, para el pueblo mapuche se trata de una relación cultural-ancestral que sustenta su propia supervivencia (Figueroa, s. f.). Comenzaron a surgir las primeras voces disidentes en torno a las limitaciones de la Conadi para enfrentar la magnitud y diversidad de las demandas, sobre todo, aquellas que tenían relación con la restitución de tierras y los proyectos macroeconómicos que se pretendían realizar en el sur del país, además de la poca voluntad política del Gobierno para avanzar en el reconocimiento de los derechos políticos (Figueroa, 2016).

Ante esta situación se reacciona con acciones diversas. La toma de terrenos, además de la quema de camiones en 1997 (Reyes, Palomera y Zamorano, 2017, marzo 19), son hechos que marcaron un antes y un después, lo que conllevó serias consecuencias en materia política respecto de la relación que el Estado estableció con el pueblo mapuche. Un exdirectivo señala que «este hecho puso al presidente en una situación difícil, pues no 
podía dejar de involucrarse, especialmente porque su proyecto se sustentaba en la confianza del sector empresarial, que denunciaba la existencia de un "estado de guerra" en la zona» (Figueroa, s. f.).

A raíz de esto se invocó por primera vez la Ley de Seguridad del Estado, lo que implicó la detención de más de diez comuneros vinculados a la quema de camiones en la zona (Figueroa, s. f. p. 8). La respuesta del Estado ante tal situación supuso la judicialización del proceso que, con el tiempo, fue incrementándose y cerró toda posibilidad de acercarse a un entendimiento mediante el diálogo. La judicialización fue la expresión de la incapacidad para gestionar las tensiones que se venían dando y con ello el fracaso de la política. Así, la judicialización fue la expresión culmen y resultado de las tensiones políticas.

\subsection{Implementación de la Central Hidroeléctrica Ralco}

Un hecho histórico y político que determinó al gobierno de Eduardo Frei fue el impacto de la implementación del proyecto Central Hidroeléctrica Ralco en Alto Bío Bío, el cual, en definitiva, significó la desestructuración de parte significativa de la cultura pehuenche. Las presiones del empresariado

[ 58 ] y las realizadas a la misma Conadi — la cual debía autorizar la permuta de terreno entre Empresa Nacional de Electricidad Sociedad Anónima (Endesa) y los propietarios de donde sería emplazada la hidroeléctrica- por actores de gobierno derivarían en la salida de dos directores de la corporación que se oponían al proyecto, dejando en evidencia la fragilidad de la institucionalidad indígena para resolver el conflicto, deslegitimando a la Conadi en su rol de coordinadora de la política indígena. Esto significó caer en una situación de intervención de la que no logró nunca reponerse institucionalmente (Figueroa, s. f.). Conadi se vio incapaz de defender la particular manera como los indígenas, en tanto comunidad diferente, quieren habitar el espacio público.

\subsection{Diálogos comunales, pueblos indígenas y judicialización}

La medida paliativa establecida por el Gobierno para intentar una salida institucional a los conflictos existentes fue la realización de una serie de diálogos comunales, establecidos para dar cuenta de cuáles eran las demandas, ya que para el Ejecutivo el problema tenía relación con el acomodo de las comunidades indígenas y con una relación causa-efecto derivada de su condición de pobreza como pueblo, lo que, a los ojos del Gobierno, requería una intervención en materia de generación de políticas 
públicas de carácter social que resolvieran la forma de salir de esta condición. Si bien fue Conadi la que condujo y coordinó la realización de estos diálogos en las regiones, la intervención del Ministerio de Desarrollo Social asumió el liderazgo, definiendo arbitrariamente los puntos de la agenda (Figueroa, 2016).

La recolección de los antecedentes dio como resultado los denominados diálogos comunales, los cuales fueron finalmente elaborados por la Comisión Asesora Presidencial, encargada de dar a conocer los principales resultados - y qué políticas debían ser las más idóneas para enfrentas las necesidades originadas desde los pueblos indígenas-. Producto de esta acción, durante el último año de gobierno de Eduardo Frei se firmó el Pacto por el Respeto Ciudadano, ${ }^{9}$ sin embargo, la exposición de este pacto que no fue firmado por todos los actores —empresariado—, terminó siendo algo meramente simbólico, lo que evidencia, una vez más, la precariedad con la que fue pensada la política indígena durante la época. Se evidencia, de este modo, la falta de voluntad para concebir las culturas ontológica, social y culturalmente distintas.

\subsection{Comisión de Verdad Histórica y Nuevo Trato}

La transición del gobierno de Eduardo Frei (1994-2000) a Ricardo Lagos (2000-2006) dio cuenta de la gran crisis de confianza que existía. Las políticas de desarrollo económicas impulsadas por el primero tensionaron hostilmente las relaciones sociopolíticas entre ambos. Por este motivo, Lagos y su equipo asesor fueron absolutamente conscientes de que algo debía hacerse en esta materia. En estas circunstancias, en enero de 2001, y a menos de un año del establecimiento del nuevo gobierno, Ricardo Lagos designó la Comisión de Verdad Histórica y Nuevo Trato (CVHNT), entidad encargada de elaborar una política de Estado con relación a los pueblos indígenas (Aylwin y Yáñez, 2007). El resultado del informe entregado en 2003 concluyó con la Política del Nuevo Trato, caracterizada básicamente por una serie de reformas jurídicas, políticas y económicas, reformas basadas en el reconocimiento colectivo

\footnotetext{
${ }^{9}$ Texto leído en español y mapuche, el cual congregó en el patio de los Naranjos en el palacio de La Moneda, entre otras autoridades, a los ministros de Estado, los presidentes del Senado, de la Cámara de Diputados y la Corte Suprema, intendentes, y a más de mil lonkos, machis y centenares de mapuches, algunos con traje autóctono. Previo al acto se realizaron rogativas con ramas de canelo (El Sur, 1999, agosto 6).
} 
de los derechos de los pueblos indígenas como medida reparatoria al daño causado históricamente.

Las tensiones producidas durante la elaboración del informe, al no considerar una serie de variables propuestas por los pueblos indígenas, especialmente el reconocimiento de su diferencia cultural y el derecho a practicarla más allá del espacio privado, tuvieron como resultado que algunos de los integrantes del mundo mapuche no lo suscribieran —Aucán Hulcamán y Galvarino Raimán, tildaron al informe de colonialista- (Figueroa, 2016). Una serie de informes y pronunciamientos internacionales tuvieron lugar en este contexto: «La situación actual de los pueblos indígenas de Chile requiere la atención urgente, no sólo del Gobierno, sino también de todos los grupos políticos, así como de la sociedad en general [...]» (Naciones Unidas. Consejo Económico y Social, Directiva General E/CN.4/2004/80/Add.2 del 23 de diciembre de 2003, p. 6). Así también, en 2004, en el informe de derechos económicos, sociales y culturales de la ONU se lamentó la falta de reconocimiento de los pueblos indígenas y que el Estado no hubiera ratificado el Convenio N. ${ }^{\circ} 169$ sobre Pueblos Indígenas y Tribales de la Organización Internacional del Trabajo (OIT) (Aylwin y Yáñez, 2007, p. 17).

[ 60 ] En este contexto, en octubre de 2003 fue entregado al presidente Ricardo Lagos el Informe de CVHNT, sin embargo, solo se dio a conocer discursivamente su anuncio seis meses después. ¿Por qué se retrasó la presentación del informe hasta abril de 2004? La evidencia indica que una de las razones tenía directa relación con las tensiones que se habían producido entre los pueblos indígenas — en especial, el pueblo mapuche- y aquellos contenidos que no fueron expuestos en el informe, tales como los derechos alusivos a la tierra, los recursos naturales y el territorio (Aylwin y Yáñez, 2007). Por otra parte, las serias complicaciones que produjo al interior del Gobierno el informe del relator de la ONU, Rodolfo Stavenhagen (2003), hizo efectivo, tal vez y por primera vez, los esfuerzos infructuosos de los gobiernos chilenos desde el retorno de la democracia. Aun cuando el contexto no era auspicioso, durante su discurso Ricardo Lagos señalaba que «El puente entre lo que hemos hecho y lo que haremos está determinado por el esfuerzo de la Comisión Aylwin. ${ }^{10}$ Ellos hicieron un alto en el camino y analizaron en profundidad el tema. Gracias a sus sugerencias creo que podemos caminar mejor [...]» (Aylwin y Yánez, 2007, p. 20).

\footnotetext{
${ }^{10}$ Nombre con el que se designó popularmente a la CVHNT.
} 
En la práctica, los resultados de la CVHNT respecto de las políticas públicas resultantes a partir de las acciones políticas tomadas no surtieron el efecto esperado y tal como señaló un parlamentario, «había un esbozo de política insuficiente y poco comprometida, hasta un poco simbólica» (Figueroa, s. f., p. 11). Por otra parte, el Consejo de Todas las Tierras hizo públicas sus denuncias respecto de la gestión unilateral y poco dialógica, «sin espacios reales para la decisión de los pueblos indígenas» (Figueroa, 2016 p. 11). El Estado se resiste a que los trasfondos culturales se instalen en el espacio público-político.

\subsection{Inundación del cementerio indígena Ralco}

Paralelamente, las políticas que impulsaba la administración de la época en materia de desarrollo productivo dificultaron los esfuerzos por mejorar las relaciones. Prueba de ello es que una semana después de anunciar la política de Nuevo Trato fue llenado el embalse del proyecto Ralco por Endesa. Como consecuencia, fue inundado el cementerio indígena Quepulca Ralco, lo que en los mapas del proyecto está consignado como el Sitio 53 (Saleh y Opazo, 2010, diciembre 6).

Ante esta situación, las movilizaciones lideradas por la Coordinadora Arauco Malleco $(\mathrm{CAM})^{11}$ y el Consejo de Todas las Tierras trajeron consigo una serie de reacciones desde el Gobierno, el mundo político y nuevamente una tensión de judicialización del proceso, lo que se conoce como la criminalización mapuche, solicitando la aplicación de la Ley de Seguridad del Estado en la denominada zona de conflicto mapuche ${ }^{12}$ y la aplicación de la denominada Ley Antiterrorista (Ley 18314). El gobierno reconoció la existencia de una estrategia de inteligencia denominada «Operación Paciencia», impulsada en contra de los mapuches con el fin de desarticular a la CAM, considerada por las autoridades de la época como «el grupo más violentista y al que se le atribuían los peores atentados» (Calbucura y Le Bonniec, 2009, p. 28). Terminado el gobierno de Lagos, el nuevo trato a los pueblos indígenas quedó relegado.

\footnotetext{
${ }^{11}$ Organización mapuche de izquierda, cuyo brazo armado son los denominados Órganos de Resistencia Territorial (ORT), los cuales hacen uso de la violencia para reivindicar el territorio y la autonomía respecto del Estado de Chile.

${ }^{12}$ Los medios de comunicación han otorgado la etiqueta de zona de conflicto mapuche (La Tercera, 2020, agosto 8).
} 


\subsection{Huelga de hambre de los comuneros mapuches}

Desde su inicio, el gobierno de Michelle Bachelet (2006-2010 y 20142018) debió enfrentar una serie de repercusiones generadas por decisiones tomadas por el gobierno anterior. Durante su campaña en 2005 visitó la Región de La Araucanía, específicamente Nueva Imperial, para la firma de un acta de Compromiso por los Pueblos Indígenas. Dicha ceremonia trajo a la memoria el Acuerdo de Nueva Imperial. El acuerdo comprometía al futuro gobierno y las organizaciones indígenas a «apoyar la candidatura presidencial de Michelle Bachelet, pues ella garantiza la protección y ampliación de nuestros derechos [...] respaldar las iniciativas de gobierno en materia indígena, considerando que nuestra participación enriquece la democracia» (Molinet, 2011, p. 51), y comprometía al gobierno a respetar las decisiones de aquellos, sus propuestas en las diversas iniciativas de proyectos de ley alusivos a salud y educción intercultural, estableciendo mecanismos apropiados para una plena y efectiva participación en los asuntos públicos (Molinet, 2011).

La primera gran crisis que vivió Bachelet estalló con la huelga de hambre de los comuneros mapuches condenados durante el gobierno anterior. La intervención de la Iglesia católica y de parlamentarios fue clave en la mediación que logró que la huelga fuera depuesta. Esto impulsó a la presidenta en su primera cuenta pública a instalar las materias indígenas pendientes, en especial, el reconocimiento constitucional de los pueblos originarios y la reivindicación de sus diversos derechos (Figueroa, s. f.).

El año 2007 marcó un antes y un después, puesto que convocó a un comisionado presidencial para Asuntos Indígenas, con el objetivo de elaborar un plan de acción y velar por el cumplimiento de todos los compromisos gubernamentales con los pueblos indígenas. Lo interesante de la creación del Comisionado es que se le hizo entrega de amplias atribuciones para formular la política indígena; sin embargo, fue un organismo centralizado que no fue socializado y tampoco abrió un espacio de diálogo participativo, por el contrario, Rodrigo Egaña - a cargo de formular la política- dirigió un amplio trabajo de revisión y crítica de las políticas en curso y de las rectificaciones consideradas indispensables. Los pueblos indígenas no fueron convocados a participar. Todo el trabajo del Comisionado se plasmó en el 
documento Re-Conocer, pacto social por la multiculturalidad (Correa, 2016, enero 7), que reflejaba un análisis realizado hasta ese momento en materia de política indígena, del cual se desprendió un plan de acción (Egaña, 2013, p. 188). Las tres grandes áreas consideraban: i) sistema político, derechos e institucionalidad; ii) desarrollo integral de los pueblos; y iii) multiculturalidad y diversidad. Se hace evidente la incapacidad para reconocer identidades que no se constituyan públicamente.

\subsection{Fallecimiento de Matías Catrileo}

Un lamentable hecho sucedió el 3 de enero de 2008. Alrededor de treinta comuneros ingresaron al Fundo Santa Margarita — propiedad de Jorge Luchinger (El Mostrador, 2008, enero 3), perteneciente a una familia de larga trayectoria en la zona de La Araucanía, un clan que, de una u otra forma, ha estado ligado al conflicto mapuche desde principios del siglo xxdonde falleció Matías Catrileo en un enfrentamiento con la policía (Figueroa, 2016, p. 13), quien se convirtió en la primera víctima de los gobiernos de la concertación en un contexto de abierto conflicto. A partir de este momento, la judicialización impidió todo proceso de interacción entre las partes.

\subsection{Proceso de ratificación del Convenio 169}

Dentro de la política Re-conocer, en marzo de 2008 se inició el proceso para el Convenio 169 de la OIT, el cual no estuvo exento de tensiones, ya que una vez que este fue aprobado por el Senado la presidenta debió ratificar. Este hecho no fue comunicado a las organizaciones indígenas del país, lo cual se tomó como una mala señal, pues existía la discusión y la intención al interior del Gobierno de ratificar el convenio con una declaración interpretativa (Molinet, 2011, p. 53).

Es importante señalar que los convenios internacionales deben ser aprobados o rechazados por el Parlamento en su integralidad, no es posible aprobar algunos artículos y rechazar otros. Lo que sí es posible es que al momento de inscribir la ratificación del país a un cierto convenio se realicen notas aclaratorias, por medio de las cuales a un determinado artículo se le haga una salvedad. Por esta razón el Senado comunicó a la presidenta una salvedad en relación con el artículo 35, que planteaba «que las disposiciones del Convenio no deberán menoscabar los derechos y ventajas garantizados 
por otros instrumentos internacionales» (Egaña, 2013, p. 182). Esto da cuenta de los intentos de los parlamentarios opositores por realizar modificaciones y de las tensiones que originaba en el Congreso aprobar el convenio.

Las tensiones entre el Ejecutivo y los partidos políticos de la oposición expresaron los esfuerzos por no dar curso y avance a la ratificación de políticas internacionales en la materia. Finalmente, la presidenta ratificó el Convenio 169 íntegramente, una señal histórica hecha por el gobierno de la Concertación (Molinet, 2011).

Durante 2009 se produjo un segundo fallecimiento. Ochenta comuneros ingresaron al Fundo San Sebastián y en un enfrentamiento con Carabineros el joven mapuche Jaime Mendoza Collio recibió un disparo por la espalda (Radio Viaducto, 2014, octubre 31). Esta fue la segunda víctima mapuche que se producía en el gobierno de Michelle Bachelet, poniendo punto final a la política indígena del gobierno (Figueroa, 2016, p. 15).

Con los hechos expuestos se da cuenta de una larga historia de tensiones entre el pueblo mapuche y el Estado chileno, que, junto a una tradición insuficiente de las políticas indígenas para reivindicar al pueblo

[ 64 ] mapuche, constituyen el marco de referencia desde cual surge no solo esta política, sino la mayoría las políticas públicas desarrolladas durante la década analizada (Luna, 2015, p. 82). Por tanto, queda de manifiesto que las tensiones originadas al interior del espacio público-político, en un contexto de democracia liberal fuertemente influida por la transición democrática, la configuración de las alianzas partidarias, las políticas públicas originadas y la relación de estas acciones con los pueblos indígenas, en especial con el pueblo mapuche, han impedido un reconocimiento multicultural en Chile durante el periodo estudiado.

\section{Discusión}

A continuación, se elabora un cuadro que tiene por objeto ilustrar los hitos políticos que se desarrollaron a lo largo de los cuatro gobiernos elegidos desde el retorno de la democracia, los hitos normativos que se sucedieron como consecuencia de estos hitos políticos y, finalmente, las tensiones que se originan. 
Cuadro 1. Hitos políticos y normativos que resumen las tensiones originadas desde el retorno a la Democracia, 1990-2010.

\begin{tabular}{|c|c|c|c|}
\hline $\begin{array}{c}\text { Periodo } \\
\text { de gobierno }\end{array}$ & Hitos políticos & Hitos normativos & $\begin{array}{l}\text { Tensiones } \\
\text { originadas }\end{array}$ \\
\hline \multirow[t]{4}{*}{$\begin{array}{l}\text { Patricio Aylwin } \\
(1990-1994)\end{array}$} & $\begin{array}{l}\text { 1. Acuerdo Nueva } \\
\text { Imperial (1989). }{ }^{13}\end{array}$ & $\begin{array}{l}\text { 1. Crea Comisión Especial } \\
\text { de Pueblos Indígenas } \\
(1990) .\end{array}$ & $\begin{array}{l}\text { 1. Construcción } \\
\text { de identidad. }\end{array}$ \\
\hline & $\begin{array}{l}\text { 2. Congreso Nacional } \\
\text { de Pueblos Indígenas } \\
(1991) .\end{array}$ & $\begin{array}{l}\text { 2. Congreso Nacional } \\
\text { de Pueblos Indígenas } \\
\text { presenta documento con } \\
\text { los principales contenidos } \\
\text { que debía incluir futura } \\
\text { Ley Indígena. }\end{array}$ & $\begin{array}{l}\text { 2. Concepciones } \\
\text { de libertad. }\end{array}$ \\
\hline & $\begin{array}{l}\text { 2.1. Gobierno Ingresa } \\
\text { nuevo proyecto } \\
\text { con modificaciones } \\
\text { realizadas por el } \\
\text { Parlamento (1992). }\end{array}$ & $\begin{array}{l}\text { 2.1. Publica Ley Indígena } \\
\text { (1993): se reconocen } \\
\text { etnias indígenas, no como } \\
\text { «pueblo». }\end{array}$ & $\begin{array}{l}\text { 2.1. Relación } \\
\text { individuo- } \\
\text { comunidad. }\end{array}$ \\
\hline & $\begin{array}{l}\text { 3. Conadi como } \\
\text { coordinador de la } \\
\text { política indígena } \\
\text { y NO como } \\
\text { interlocutor válido. }\end{array}$ & $\begin{array}{l}\text { 3. Corporación de } \\
\text { Desarrollo Indígena } \\
\text { Conadi. }^{14}\end{array}$ & $\begin{array}{l}\text { 3. Construcción } \\
\text { de identidad. }\end{array}$ \\
\hline \multirow[t]{3}{*}{$\begin{array}{l}\text { Eduardo Frei } \\
(1994-2000)\end{array}$} & $\begin{array}{l}\text { 4. Primeras tomas de } \\
\text { terrenos por parte de } \\
\text { indígenas que apoyan } \\
\text { causa Mapuche. }\end{array}$ & $\begin{array}{l}\text { 4. Se invoca por primera } \\
\text { vez Ley de Seguridad del } \\
\text { Estado. }\end{array}$ & $\begin{array}{l}\text { 4. Judicialización } \\
\text { del proceso. }\end{array}$ \\
\hline & $\begin{array}{l}\text { 5. Implementación } \\
\text { Central Hidroeléctrica } \\
\text { Ralco. }\end{array}$ & $\begin{array}{l}\text { 5. Aprobación del } \\
\text { proyecto por parte de la } \\
\text { institucionalidad vigente } \\
\text { Conadi. }\end{array}$ & $\begin{array}{l}\text { 5. Relación } \\
\text { individuo- } \\
\text { comunidad. }\end{array}$ \\
\hline & $\begin{array}{l}\text { 6. Rompe el diálogo } \\
\text { pueblos indígenas, } \\
\text { asociado al uso } \\
\text { de la violencia y } \\
\text { judicialización de los } \\
\text { procesos. }\end{array}$ & $\begin{array}{l}\text { 6. Implementación } \\
\text { diálogos comunales, } \\
\text { teniendo como producto } \\
\text { final el Pacto por el } \\
\text { Respeto Ciudadano. }\end{array}$ & $\begin{array}{l}\text { 6. El lugar de la } \\
\text { cultura. }\end{array}$ \\
\hline
\end{tabular}

${ }^{13}$ Se considera hito político debido a que se encontraba el presidente Aylwin en campaña durante 1989, y es en esa fecha cuando se realizó el Acuerdo de Nueva Imperial, por tanto, para efectos del estudio, aunque es anterior a 1990, se considera como hito político que antecede al hito normativo de 1990 para la creación de la CEPI.

${ }^{14}$ Conadi se creó dentro de la Ley Indígena. 
Cuadro 1. (Continuación)

\begin{tabular}{|c|c|c|c|}
\hline $\begin{array}{c}\text { Periodo } \\
\text { de gobierno }\end{array}$ & Hitos políticos & Hitos normativos & $\begin{array}{l}\text { Tensiones } \\
\text { originadas }\end{array}$ \\
\hline \multirow[t]{2}{*}{$\begin{array}{l}\text { Ricardo Lagos } \\
(2000-2006)\end{array}$} & $\begin{array}{l}\text { 7. Comisión } \\
\text { de Verdad Histórica } \\
\text { y Nuevo Trato. }\end{array}$ & $\begin{array}{l}\text { 7. Política Indígena } \\
\text { del Nuevo trato. }\end{array}$ & $\begin{array}{l}\text { 7. El lugar } \\
\text { de la cultura. }\end{array}$ \\
\hline & $\begin{array}{l}\text { 8. Inundación } \\
\text { cementerio indígena } \\
\text { en Ralco. }\end{array}$ & $\begin{array}{l}\text { 8. Se aprueba Política } \\
\text { de Desarrollo Productivo } \\
\text { Embalse Ralco. }\end{array}$ & $\begin{array}{l}\text { 8. Judicialización } \\
\text { del proceso. }\end{array}$ \\
\hline \multirow[t]{3}{*}{$\begin{array}{l}\text { Michelle Bachelet } \\
(2006-2010)\end{array}$} & $\begin{array}{l}\text { 9. Huelga de } \\
\text { hambre comuneros } \\
\text { mapuches. Se } \\
\text { crea Comisionado } \\
\text { Presidencial para } \\
\text { Asuntos Indígenas. }\end{array}$ & $\begin{array}{l}\text { 9. Documento } \\
\text { Re-conocer, pacto social } \\
\text { por la multiculturalidad. }\end{array}$ & $\begin{array}{l}\text { 9. Construcción } \\
\text { de identidad. }\end{array}$ \\
\hline & $\begin{array}{l}\text { 10. Fallecimiento } \\
\text { Matías Catrileo y } \\
\text { fallecimiento Jaime } \\
\text { Mendoza Collío. }\end{array}$ & $\begin{array}{l}\text { 10. Política Inteligencia } \\
\text { Policial en zona de } \\
\text { Conflicto. }\end{array}$ & $\begin{array}{l}10 . \\
\text { Judicialización } \\
\text { del proceso. }\end{array}$ \\
\hline & $\begin{array}{l}\text { 11. Comienza } \\
\text { proceso ratificación } \\
\text { Convenio } 169 .\end{array}$ & $\begin{array}{l}\text { 11. Ratifica Convenio } 169 \\
\text { de la OIT. }\end{array}$ & $\begin{array}{l}\text { 11. Construcción } \\
\text { de identidad. }\end{array}$ \\
\hline
\end{tabular}

Fuente: elaboración propia.

A la luz de los antecedentes expuestos, existe una percepción generalizada en el país en cuanto a que la institucionalidad del Estado en materia indígena se encuentra en crisis y requiere ser replanteada (Centro de Políticas Públicas UC, 2015, p. 6). Esta debería hacer propia el diálogo y deliberación para estar a la altura de las exigencias que demanda una sociedad multicultural como la chilena.

Este análisis ha permitido dar cuenta de cómo el Estado, más que buscar un reconocimiento real y apertura al diálogo, ha profundizado las tensiones existentes. La presencia de los pueblos indígenas en lo público-político está condicionada por las formas y mecanismos que la misma estructura estatal determina y establece como legítimas para responder o no a las demandas reivindicativas. La diversidad se reconoce en el marco de un universalismo que tolera aquello distinto, pero que no reconoce su particularidad. 
Esta práctica política que restringe epistémica y socialmente al otro conlleva la necesidad y el desafío de aportar a las discusiones actuales que existen en esta materia, para avanzar hacia una política de reconocimiento multicultural donde se recupere el sentido de la política y permita construir dialógicamente nuevas formas de ver las problemáticas, para que puedan ser traducidas a políticas públicas acordes a la realidad actual.

Así las cosas, es pertinente evidenciar que en la actualidad la concepción política considerada como estructura básica en la sociedad chilena y también de gran parte de América Latina es insuficiente para responder a las demandas sobre reconocimiento, dado que la misma estructura, se encuentra en una tensión — como lo denomina Rawls (1995), tensión de compromisos- al interior del espacio público.

Si el liberalismo aspira a una igualdad de condiciones ha de poner en marcha políticas de reconocimiento igualitario, que impliquen derechos iguales para todos, pero esa igualdad - y este punto es de crítica importanciano necesariamente debería ser materializada por todos del mismo modo, ya que no se puede concebir la pluralidad de contextos culturales al margen de formas propias de organización y participación en los asuntos públicopolíticos. Tratar a todos con igualdad implica aceptar el particularismo del otro (Taylor, 1997).

La dinámica política que ha mostrado el análisis ha devenido en una concepción y práctica empirista, realista y procesual de la política orientada por un principio de eficacia, donde la racionalidad dominante se ha constituido en imperativo que ha ido socavando las condiciones para una democracia participativa. La política debe volver a entroncar con los mundos de la vida, huérfanos del espacio público-político desde que el Estado de derecho como expresión de la razón pública, ha desplazado a los otros más allá de los límites de lo legitimado. El liberalismo se diluye producto de su propia concepción de razón: creer que la razón es autogeneradora de lo que hay, sin advertir que esta no se sostiene en ella misma; también requiere lo que ella pretende no ser, de su cultura y de las otras culturas. Lo anterior se sustenta a la luz del contexto chileno y los antecedentes histórico-políticos que ya se han advertido.

Esto se evidencia en la judicialización del proceso, como expresión de cómo la estructura estatal, al no ser capaz de dar una solución efectiva 
mediante los instrumentos institucionales establecidos, decide judicializarlos, lo que finalmente acentúa las dificultades para la necesaria cooperación social. La carencia de sensibilidad moral, de recursos y de prácticas políticas acordes a los desafíos étnico-sociales dificulta una política que haga eco de las demandas de reconocimiento de la diversidad sociocultural. Los antecedentes indican que producto de la radicalización de las tensiones, se dan nuevas formas de politización de los pueblos indígenas que en la práctica se han transformado en el uso de violencia política como forma de reivindicación étnica (Pairicán y Álvarez, 2011).

Para Taylor (2009), el reconocimiento público de identidades diferentes ha de ser una obligación de la política. El sentir de las identidades colectivas y la apertura de las instituciones hacia una visión de mundo, no solo política sino también moral, puede dar lugar a la generación de un espacio de libertad. La dignidad de los seres libres e iguales exige que las instituciones democráticas liberales no sean represivas ni discriminatorias, y sí, en cambio, deliberativas (Taylor, 2009, p. 36). En este sentido, las diversidades pasarían a instalarse en el centro del debate; ya no serían meros o problemáticos anexos que se entenderían y legitimarían a partir de la lógica del todo, lo homogéneo, la cultura pública. La diversidad puede constituirse en tema de la agenda público-política, constituyéndose, por tanto, en objeto de la reflexión. La presencia de diversas narrativas con sus distintas memorias, —también y particularmente aquéllas articuladas a partir de un perjuicio compartido, producto en no pocos casos del menosprecio sufrido por la ausencia o falso reconocimiento-, dotarían de espesor e historicidad a las posibilidades que tradicionalmente el espacio públicopolítico ha desplegado, dando pie de este modo, a reflexionar sobre las condiciones de formación de este, sus reglas de juego, los fines que persigue, además de las construcciones ontológicas en que descansa, y con ello poder desbordar sus actuales límites y limitaciones.

Para Taylor (1997) la igualdad, la participación política y los derechos son los fundamentos intocables de lo estatal y en esto coincide con las tesis liberales clásicas. La diferencia proviene de su concepción holista de la identidad, frente al atomismo liberal clásico, que implica el derecho a la participación política activa de los distintos grupos desde sus particularidades, al ser esta parte de los fundamentos del Estado (Taylor, 1994). Con esto se solventaría el peligro de la pérdida de identidad que genera el universalismo liberal. 
Pero si bien las tesis multiculturalistas pueden ayudar a superar los límites, no dan cuenta del trasfondo histórico del problema y tampoco el camino que proponen es del todo realista. En primer lugar, hay que recordar que las dinámicas de exclusión no descansan exclusivamente en las experiencias de menosprecio, sino dependen de estructuras socioeconómicas (Tubino, 2015, Walsh, 2009). Por otra parte, ¿cómo en un mundo de creciente emergencia y visibilización de diversidad e intradiversidad se puede responder sin violencia a la pregunta de quiénes somos y a qué aspiramos? Parece realmente difícil la conformación de una identidad ligada no problemáticamente a una cultura política reivindicativa, que en caso de ser conformada contiene el peligro de la esencialización de la cultura.

\section{Conclusiones}

En el Chile actual, a raíz del estallido social del 18 de octubre de 2019, han quedado en evidencia las diversas demandas que la sociedad chilena ha planteado a sus gobernantes, entre ellas, las del reconocimiento indígena. Para ello, la oportunidad de avanzar en una Nueva Constitución política - en caso de aprobarse el plebiscito sobre Nueva Constitución el 25 de octubre de 2020- puede constituir un paso necesario en el reconocimiento constitucional de los pueblos indígenas en Chile, constituyéndose así en un país multicultural dentro de una democracia representativa liberal. Una Nueva Constitución política sería el cuerpo legal que puede desarrollar una visión multicultural que respete la diversidad, reconociéndola como aspecto esencial de la república, pudiéndose de este modo oxigenar las tensiones que hemos identificado: la silenciada voz del otro puede participar en las prácticas deliberativas. Sin embargo, estos cambios por sí mismos no pueden resolver la problemática, ya que su participación se llevaría a cabo en el marco de unas reglas de juego de las que no fueron partícipes.

Segundo, a partir del rediseño jurídico es necesario reestructurar la institucionalidad vigente que rige en la actualidad a los pueblos indígenas, como la Conadi. De esta manera, su reestructuración debe basarse en una representación verdadera y fidedigna, además de aplicar de manera correcta el Convenio $N^{\circ} 169$ que protege los derechos indígenas, el respeto a sus valores, prácticas y medios necesarios para la participación indígena (Centro de Políticas Públicas UC, 2015), generando garantías para los procesos de diálogo, tal y como lo establece el Convenio en el artículo 6. 
Por último, se debe considerar que la dimensión institucional no solo debe ser centralizada, tomando un enfoque top-down, sino más bien una política pública institucional con características bottom-up, es decir, que considere tanto a los gobiernos regionales, así como a las municipalidades, los cuales se encuentran en vinculación directa con los pueblos indígenas y, en especial, con comunidades representativas y validadas por ellos mismos.

Avanzar en un reconocimiento constitucional mediante una nueva constitución política otorgaría mayor peso a la creación de un ministerio de asuntos indígenas que considere funciones y atribuciones autónomas en materia de toma de decisiones, incluyendo como representantes válidos a los pueblos indígenas, generando un equilibrio entre representantes del Ejecutivo y que otorgue poder de decisión vinculante a aquellos que representen los intereses de sus respectivos pueblos.

Si se pretende avanzar hacia una sociedad verdaderamente democrática dentro de un país con características representativas liberales, no se puede pasar por alto el reconocimiento de identidades diversas y seguir construyendo políticas públicas basadas en una identidad dominante, mayoritaria y pensada en derechos universales que continúan siendo ciegos a la diferencia.

\section{Referencias bibliográficas}

1. Arendt, Hannah. (1997). ¿Qué es política? Barcelona: Paidós.

2. Arregui, Jorge. (1997, junio 29). Una razón pública o pluralidad de razones prácticas. Nueva Revista. Recuperado de https://www.nuevarevista.net/libros/unarazon-publica-o-pluralidad-de-razones-practicas/

3. Aylwin, José y Yáñez, Nancy. (2007). El gobierno de Lagos, los pueblos indígenas y el "nuevo trato». Las paradojas de la democracia chilena. Santiago: LOM.

4. Aylwin, Patricio. (1989). Acuerdo Nueva Imperial: Acta de compromiso. Fundación Patricio Aylwin. Recuperado de http://fundacionaylwin.cl/wp-content/ uploads/2018/06/2.-Acuerdo-Nuevalmperial_1dic1989.pdf

5. Bauman, Zygmunt. (2000). Modernidad líquida. Buenos Aires: Fondo de Cultura Económica. LOM.

6. Bengoa, José. (2008). Historia del pueblo mapuche. Siglo xIx y xx. Santiago:

7. Boccara, Guillaume y Seguel-Boccara, Ingrid. (1999). Políticas indígenas en Chile (siglos xIx y xx) de la asimilación al pluralismo (el caso mapuche). Revista de Indias, LIX (217), pp. 741-774. Recuperado de https://doi.org/10.3989/revindias.1999. i2 217.834 
8. Calbucura, Jorge y Le Bonniec, Fabien (eds.). (2009). Territorio y territorialidad en contexto post-colonial. Estado de Chile-Nación Mapuche. Estocolmo: Ñuke Mapuförlaget.

9. Centro de Políticas Públicas UC. (2015). Nueva institucionalidad indígena y sus repercusiones para la aplicación del Convenio N. ${ }^{\circ} 169$ de la OIT. Temas de la Agenda Pública. 10 (77). Recuperado de https://politicaspublicas.uc.cl/wp-content// uploads/2015/05/N\%C2\%B0-77-Nueva-institucionalidad-ind\%C3\%ADgena-y-susrepercusiones-para-la-aplicaci\% C3\%B3n-del-Convenio-N\%C2\%B0-169-de-la-OIT. pdf

10. Chile. Ministerio de Planificación y Cooperación Social. Ley 19253 (5, octubre, 1993). Establece normas sobre protección, fomento y desarrollo de los indígenas, y crea la Corporación Nacional de Desarrollo Indígena. Diario Oficial. Santiago, 1993, N. ${ }^{\circ}$ 34683. pp. 2-8.

11. Chile. Ministerio del Interior. Ley 18314 (17, junio, 1984). Determina conductas terroristas y fija su penalidad. Diario Oficial. Santiago, 1984, N. ${ }^{\circ} 29731$.

12. Chile. Ministerio Secretaría General de la Presidencia. Decreto Supremo 30 (17, mayo, 1990). Crea Comisión Especial de Pueblos Indígenas. Recuperado de https:// www.leychile.cl/Navegar? idNorma = 7833\&idParte = \&idVersion = 1995-04-26

13. Cohen, Elizabeth. (2009). Semi-Citizenship in Democratic Politics. New York: Cambridge University. https://doi.org/10.1017/CBO9780511642333

14. Correa, Antonio. (2016, enero 7). Bachelet y los pueblos indígenas. El Mostrador. Recuperado de http://www.elmostrador.cl/noticias/opinion/2016/01/07/ bachelet-y-los-pueblos-indigenas/

15. Correa, Antonio. (2017, marzo 12). Nueva ley indígena urgente. El Mostrador. Recuperado de https://www.elmostrador.cl/noticias/opinion/2017/03/12/nueva-leyindigena-urgente/

16. Díaz-Polanco, Héctor. (2006). Elogio de la diversidad. Globalización, multiculturalismo y etnofagia. México, D. F.: Siglo xxı.

17. Egaña, Rodrigo. (2013). Convenio 169 y su implementación. La propuesta del gobierno Bachelet (2006-2010). Estado, Gobierno y Gestión Pública. 21, pp. 179211. DOI: 10.5354/0717-8980.2013.29406

18. El Mostrador. (2008, enero 3). Comunero mapuche muere en enfrentamiento con Carabineros. https://www.elmostrador.cl/noticias/pais/2008/01/03/comuneromapuche-muere-en-enfrentamiento-con-carabineros-2/

19. El Sur. (1999, agosto 6). Gobierno lanzó plan de ayuda para mapuches. Recuperado de http://www.mapuche.info/news01/dsur990806.html

20. Etchegaray, Ricardo. (2014). La filosofía política de Jacques Rancière. Nuevo Pensamiento, Iv, pp. 25-60.

21. Figueroa, Verónica. (2016). Pueblos indígenas y políticas públicas. El proceso de formulación de la política indígena en Chile en el gobierno de Eduardo Frei RuizTagle, 1994-2000. Gestión y Política Pública. 25 (2), pp. 447-482. 
22. Figueroa, Verónica. (s. f.). El proceso de formulación de políticas públicas indígenas en Chile: la necesidad de nuevos marcos de análisis. Fundación Henry Dunant. Recuperado de https://www.fundacionhenrydunant.org/images/stories/ biblioteca/Derechos \% 20Humanos \% 20y\% 20Constituci \% C3\% B3n/Politicas \% 20 Publicas $\% 20 \% 20$ Ind $\%$ C $3 \%$ ADgenas-Nuevos $\% 20$ marcos $\% 20$ de $\%$ 20analisis_ Veronica\%20Figueroa\%20Huencho.pdf

23. Huntington, Samuel. (1996). El choque de civilizaciones y la reconfiguración del orden mundial. Nueva York: Simon \& Schuster.

24. La Tercera. (2020, agosto 8). Historia y conflicto mapuche: Diálogo con Elicura Chihuailaf y José Bengoa. La Tercera. https://www.latercera.com/conversacioneslt/ noticia/historia-y-conflicto-mapuche-dialogo-con-elicura-chihuailaf-y-jose-bengoa/ MQZTFOCITZBXRPCLNCLRMFCPIQ/

25. Luna, Roxana. (2015). Rol del Estado chileno en la definición de políticas indígenas durante los gobiernos de la concertación. Discursos del pueblo mapuche williche frente al programa orígenes, segunda fase, 2008-2010, gobierno de Michelle Bachelet. (Tesis inédita de maestría). Universidad de Chile, Santiago.

26. Meer, Nasar y Monood, Tariq. (2012). How does Interculturalism Contrast with the Multiculturalism. Journal of Intercultural Studies. 33 (2), pp. 175-196. https:// doi.org/10.1080/07256868.2011.618266

27. Molinet, Soledad. (2011). La política indígena chilena durante los gobiernos de la Concertación (1990-2009): una mirada desde la dirigencia mapuche de la región de La Araucanía. (Tesis inédita de maestría). Universidad Alberto Hurtado, Santiago.

28. Naciones Unidas. Consejo Económico y Social. Directiva General E/ CN.4/2004/80/Add.2. (23, diciembre, 2003). Informe del Relator Especial sobre la situación de los derechos humanos y las libertades fundamentales de los indígenas, Sr. Rodolfo Stavenhagen. Recuperado de https://www.acnur.org/fileadmin/Documentos/ BDL/2006/4357.pdf

29. Pairicán, Fernando. (2014). Malón. La rebelión del movimiento mapuche 1990-2013. Santiago: Pehuén.

30. Pairicán, Fernando y Álvarez, Rolando. (2011). La Nueva Guerra de Arauco: La Coordinadora Arauco Malleco en el Chile de la Concertación de Partidos por la Democracia (1997-2009). Revista Izquierdas. 10, pp. 66-84.

31. Pavez, Jorge. (2008). Cartas mapuche. Siglo XIX. Santiago: Ocho Libros, CoLibris.

32. Pinto, Jorge. (2000). De la inclusión a la exclusión. la formación del estado, la nación y el pueblo mapuche. Santiago: Universidad de Santiago de Chile.

33. Radio Viaducto. (2014, octubre 31). Preparan funeral de comunero asesinado. Radio Viaducto. Recuperado de https://radioviaducto.cl/web/preparan-funeral-decomunero-asesinado/

34. Rawls, John. (1995). Liberalismo Político. México, D. F.: Fondo de Cultura Económica. 
35. Reyes, C.; Palomera, F. y Zamorano, C. (2017, marzo 19). Los 20 años del conflicto en La Araucanía: ¿Qué viene ahora? La Tercera. Recuperado de https://www. latercera.com/noticia/los-20-anos-del-conflicto-la-araucania-viene-ahora/

36. Rincón, Tatiana. (2008). Pluralidad en la esfera público político. Estudios de Filosofía, III Congreso Iberoamericano de Filosofía Memorias Pluralismo, pp. 203-217.

37. Saleh, Felipe y Opazo, Julia. (2010, diciembre 6). El cementerio indígena que incomoda a Endesa. El Mostrador. Recuperado de https://www.elmostrador.cl/ noticias/pais/2010/12/06/el-cementerio-indigena-que-incomoda-a-endesa/

38. Sandel, Michael. (2000). El liberalismo y los límites de la justicia. Barcelona: Gedisa.

39. Strauss, Anselm y Corbin, Juliet. (2002). Bases de la investigación cualitativa: técnicas y procedimientos para desarrollar la teoría fundamentada. Medellín: Universidad de Antioquía.

40. Taylor, Charles. (1994). Ética de la autenticidad. Barcelona: Paidós.

41. Taylor, Charles. (1997). Argumentos filosóficos. Ensayos sobreel conocimiento, el lenguaje y la modernidad. Barcelona: Paidós.

42. Taylor, Charles. (2009). El multiculturalismo y «la política del reconocimiento». México, D. F.: Fondo de Cultura Económica.

43. Tubino, Fidel. (2015). La interculturalidad en cuestión. Lima: PUCP.

44. Walsh, Catherine. (2009). Interculturalidad, Estado, sociedad. Luchas (de) coloniales de nuestra época. Quito: Universidad Andina Simón Bolívar.

45. Zavala, José Manuel (ed.). (2015). Los parlamentos hispano-mapuches, 15931803: Textos fundamentales. Temuco: Universidad Católica de Temuco. 